九州大学学術情報リポジトリ

Kyushu University Institutional Repository

\title{
Accumulation of Digestible Materials and Decrease in Dry Matter Digestibility in the Growth of Two Tropical Grasses
}

Shimojo, Masataka

Laboratory of Animal Feed Science, Faculty of Agriculture, Kyushu University

Bungo, Takashi

Laboratory of Animal Feed Science, Faculty of Agriculture, Kyushu University

Tobisa, Manabu

Laboratory of Animal Feed Science, Faculty of Agriculture, Kyushu University

Imura, Yoshimi

Laboratory of Animal Feed Science, Faculty of Agriculture, Kyushu University

他

https://doi.org/10.5109/24225

出版情報 : 九州大学大学院農学研究院紀要. 42 (3/4)，pp. 365-372，1998-03. Kyushu University バージョン：

権利関係 : 


\section{Accumulation of Digestible Materials and Decrease in Dry Matter Digestibility in the Growth of Two Tropical Grasses}

\section{Masataka Shimojo, Takashi Bungo, Manabu Tobisa, Yoshimi Imura, Naoki Koga, Shao Tao, Muhammad Yunus, Zhao Yin, Yutaka Nakano*, Ichiro Goto and Yasuhisa Masuda}

Laboratory of Animal Feed Science, Faculty of Agriculture, Kyushu University, Fukuoka 812-8581, Japan

(Received November 28, 1997 and accepted December 3, 1997)

This study was conducted to analyze the accumulation of digestible materials from digestible materials present in forage and new photosynthates and to analyze the decrease in dry matter digestibility with growth of two tropical grasses, using the following two equations.

$$
\begin{aligned}
& \frac{1}{W} \cdot \frac{d D}{d t}=\left(\frac{1}{D+\frac{d W}{d t}} \cdot \frac{d D}{d t}\right) \cdot \frac{D+\frac{d W}{d t}}{W}, \\
& \frac{D_{1}}{W_{1}}-\frac{D_{2}}{W_{2}}=\left(1-\frac{W_{1}}{W_{2}}\right) \cdot\left(\frac{D_{1}}{W_{1}}-\frac{\overline{\mathrm{ARD}}}{\overline{\mathrm{RGR}}}\right),
\end{aligned}
$$

where $W=$ dry weight of forage $\left(W_{1} \neq W_{2}\right), D=$ dry weight of digestible materials $\left(D_{1} \neq D_{2}\right)$, $d W / d t=$ new photosynthates, $(D+d W / d t)=$ amount of source materials [S] for $D$ accumulation, $(1 / W) \cdot(d D / d t)=$ accumulation rate of $D$ per unit $W[\mathrm{ARD}],\{1 /(D+d W / d t)\} \cdot(d D / d t)=$ accumulation rate of $D$ per unit $S[\operatorname{ARDS}],(D+d W / d t) / W=$ the ratio of $S$ to $W$ [S ratio], $\overline{\mathrm{RGR}^{*}}=$ mean relative growth rate of forage, $\left(1-W_{1} / W_{2}\right)=$ forage growth index $\left[\mathrm{FG}\right.$ index], $\left(D_{1} / W_{1}-\right.$ $\overline{\mathrm{ARD}} / \overline{\mathrm{RGR}_{\mathrm{w}}}$ ) $=$ index for the decrease in dry matter partition into digestible materials [DDMPD index], $D_{1} / W_{1}-D_{2} / W_{2}=$ the decrease in dry matter digestibility [DDMD].

Two equations were applied to dallis grass (Dg) and bermuda grass (Bg) cut at 20,59 and 80 days of regrowth. Each attribute in two equations was given a bar on it to show mean value over the 1st interval of 39 days and over the 2nd interval of 21 days, respectively. The following results were obtained:

1. Dg: Higher $\overline{\mathrm{ARD}}$ in the 1st interval compared to the 2nd interval was due to higher $\overline{\mathrm{ARDS}}$ in the 1st interval. Similar DDMD between two intervals was due to the offset effect between FG index and DDMPD index.

2. $\mathrm{Bg}$ : Lower $\overline{\mathrm{ARD}}$ in the 1st interval than in the 2nd interval was due to lower $\overline{\mathrm{ARDS}}$ in the 1st interval. The larger DDMD in the 1st interval compared to the 2 nd interval was due to higher DDMPD index in the 1st interval.

3. 1st interval: Higher $\overline{\mathrm{ARD}}$ in Dg than in Bg was mainly due to higher $\overline{\mathrm{ARDS}}$ in Dg. Almost the same DDMD between Dg and Bg was due to the offset effect between FG index and DDMPD index.

4. 2nd interval: Lower $\overline{\mathrm{ARD}}$ in Dg than in Bg was due to lower $\overline{\mathrm{ARDS}}$ in Dg. The larger DDMD in Dg compared to $\mathrm{Bg}$ was due to higher DDMPD index in Dg.

It was suggested that the proposed method gave macro analyses of the accumulation of digestible materials and the decrease in dry matter digestibility with growth of tropical grasses.

\footnotetext{
* Kyushu University Farm, Fukuoka 811-2307.
} 


\section{INTRODUCTION}

The decrease in dry matter digestibility that occurs with growth of forage is caused by the increase in the proportion of indigestible materials (Van Soest, 1982; Minson, 1990). There are some analytical studies, using simple equations, on the formation of indigestible materials and increases in dry matter indigestibility in the growth of tropical forages (Masuda, 1985; Shimojo et al., 1995; Shimojo et al., 1997a; Shimojo et al., 1997b; Shimojo et al., 1998a; Shimojo et al., 1998b).

In one report (Shimojo et al., 1998a) of these studies, the formation of indigestible materials was analyzed in relation to the formation from source materials which were composed of digestible materials present in forage and new photosynthates. The remainder of source materials after the formation of indigestible materials is involved in the accumulation of digestible materials. The accumulation of digestible materials from source materials, however, does not appear to be elucidated analytically.

This study was designed, using two tropical grasses, to make an analytical approach to the accumulation of digestible materials from digestible materials present in grasses and new photosynthates, and to give analytical description of the decrease in dry matter digestibility.

\section{METHODS FOR ANALYZING ACCUMULATION OF DIGESTIBLE MATERIALS AND DECREASE IN DRY MATTER DIGESTIBILITY}

\section{Accumulation of digestible materials}

In this study the accumulation rate of digestible materials [ARD] in forage is taken up as follows in the same way as the production rate of leaf, stem or root in plant (Hunt, 1990).

Thus,

$$
\mathrm{ARD}=\frac{1}{W} \cdot \frac{d D}{d t},
$$

where $W=$ dry weight of forage, $D=$ dry weight of digestible materials.

The digestible materials are actually accumulated from source materials which are composed of digestible materials present in forage and new photosynthates. Thus, accumulation rate of $D$ per unit weight of source materials [ARDS] is taken up as follows:

$$
\operatorname{ARDS}=\frac{1}{D+\frac{d W}{d t}} \cdot \frac{d D}{d t}
$$

where $d W / d t=$ new photosynthates, $D+d W / d t=$ amount of source materials $[\mathrm{S}]$ for $D$ accumulation.

Combining equations (1) and (2) gives

$$
\frac{1}{W} \cdot \frac{d D}{d t}=\left(\frac{1}{D+\frac{d W}{d t}} \cdot \frac{d D}{d t}\right) \cdot \frac{D+\frac{d W}{d t}}{W},
$$

where $(D+d W / d t) / W=$ the ratio of $S$ to $W[\mathrm{~S}$ ratio].

Equation (3) shows that ARD is expressed as the product of ARDS and $\mathrm{S}$ ratio. 
The mean value over the interval $t_{1}$ to $t_{2}$ for each of ARD, ARDS and $\mathrm{S}$ ratio is approximately as follows:

$$
\begin{aligned}
& \overline{\mathrm{ARD}}=\frac{\log _{e} W_{2}-\log _{e} W_{1}}{W_{2}-W_{1}} \cdot \frac{D_{2}-D_{1}}{t_{2}-t_{1}}, \\
& \overline{\mathrm{ARDS}}=\frac{1}{\frac{D_{2}-D_{1}}{\log _{e} D_{2}-\log _{e} D_{1}}+\frac{W_{2}-W_{1}}{t_{2}-t_{1}} \cdot \frac{D_{2}-D_{1}}{t_{2}-t_{1}},} \\
& \overline{\text { S ratio }}=\left(\frac{D_{2}-D_{1}}{\log _{e} D_{2}-\log _{e} D_{1}}+\frac{W_{2}-W_{1}}{t_{2}-t_{1}}\right) \cdot \frac{\log _{e} W_{2}-\log _{e} W_{1}}{W_{2}-W_{1}},
\end{aligned}
$$

where $e=$ the base of natural logarithm, $W_{1} \neq W_{2}, D_{1} \neq D_{2}$.

\section{Decrease in dry matter digestibility}

The decrease in dry matter digestibility [DDMD] over the interval $t_{1}$ to $t_{2}$ is described as follows:

$$
\mathrm{DDMD}=\frac{D_{1}}{W_{1}}-\frac{D_{2}}{W_{2}}
$$

The right side of equation (7) is rewritten as follows:

$$
\begin{aligned}
\frac{D_{1}}{W_{1}}-\frac{D_{2}}{W_{2}} & =\frac{D_{1}}{W_{1}}-\frac{D_{1}+\Delta D}{W_{1}+\Delta W} \\
& =\frac{D_{1} \cdot \Delta W}{W_{1} \cdot\left(W_{1}+\Delta W\right)}-\frac{\Delta D}{W_{1}+\Delta W} \\
& =\frac{D_{1} \cdot \Delta W}{W_{1} \cdot W_{2}}-\frac{\Delta D}{W_{2}} \\
& =\frac{\Delta W}{W_{2}} \cdot\left(\frac{D_{1}}{W_{1}}-\frac{\Delta D}{\Delta W}\right) .
\end{aligned}
$$

Here the ratio of ARD to relative growth rate of forage $\left[\mathrm{RGR}_{\mathrm{w}}\right]$ is taken up as follows:

$$
\begin{aligned}
\frac{\mathrm{ARD}}{\mathrm{RGR}_{W}} & =\frac{\frac{1}{W} \cdot \frac{d D}{d t}}{\frac{1}{W} \cdot \frac{d W}{d t}} \\
& =\frac{d D}{d W} .
\end{aligned}
$$

Thus, the following relation is obtained,

$$
\frac{\Delta D}{\Delta W}=\frac{\overline{\mathrm{ARD}}}{\overline{\mathrm{RGR}_{\mathrm{W}}}},
$$

where $\overline{\mathrm{RGR}_{\mathrm{w}}}=$ mean RGRw over the interval $t_{1}$ to $t_{2}$.

Inserting equation (10) into equation (8) gives 
$\frac{D_{1}}{W_{1}}-\frac{D_{2}}{W_{2}}=\left(1-\frac{W_{1}}{W_{2}}\right) \cdot\left(\frac{D_{1}}{W_{1}}-\frac{\overline{\mathrm{ARD}}}{\overline{\mathrm{RGR}_{\mathrm{W}}}}\right)$,

where $W_{1} \neq W_{2},\left(1-W_{1} / W_{2}\right)=$ forage growth index [FG index],

$\left(D_{1} / W_{1}-\overline{\mathrm{ARD}} / \overline{\mathrm{RGR}_{\mathrm{w}}}\right)=$ index for the decrease in dry matter partition into digestible materials [DDMPD index].

As shown in equation (7), DDMD is expressed using a complex of $W$ and $D$ which are connected inseparably. FG index is a factor of forage production that is taken compulsorily out of the complex, therefore, DDMPD index as a factor of partition inevitably includes $\mathrm{RGR}_{w}$ to complete the inseparable connection. Thus, equation (11) shows that DDMD is expressed as the product of FG index and DDMPD index.

\section{APPLICATION OF ANALYTICAL METHOD TO TWO TROPICAL GRASSES}

Characteristics of dallis grass (Paspalum dilatatum Poir.) and bermuda grass (Cynodon dactylon (L.) Pers.) are shown in Table 1. Dallis grass (Dg) and bermuda grass $(\mathrm{Bg})$ were cut at 20,59 and 80 days of regrowth after the first cut and discard followed immediately by the dressing of a compound fertilizer $\left(\mathrm{N}_{2} \mathrm{P}_{2} \mathrm{O}_{5}: \mathrm{K}_{2} \mathrm{O}=14: 14: 14 \%\right)$ at a rate of $0.7 \mathrm{~kg} / \mathrm{a}$ for each element. The first interval was 39 days (20 to 59 days) and the second interval was 21 days ( 59 to 80 days), respectively.

Comparisons of analyses were made between two intervals in each of two grasses and made between two grasses in each of two intervals.

Table 1. Characteristics of dallis grass and bermuda grass.

a) Dallis grass.

\begin{tabular}{lrrr}
\hline Regrowth (days) & \multicolumn{1}{c}{20} & \multicolumn{1}{c}{59} & \multicolumn{1}{c}{80} \\
\hline Dry matter digestibility: $(\%)$ & 72.25 & 59.78 & 45.81 \\
Dry weight of forage: $W\left(\mathrm{~g} / \mathrm{m}^{2}\right)$ & 213.20 & 676.53 & 780.40 \\
Dry weight of digestible materials: $D\left(\mathrm{~g} / \mathrm{m}^{2}\right)$ & 154.04 & 404.43 & 357.50 \\
\hline
\end{tabular}

Dry matter digestibility: determined in vitro using rumen fluid of goats and pepsin.

b) Bermuda grass.

\begin{tabular}{lrrr}
\hline Regrowth (days) & 20 & 59 & \multicolumn{1}{c}{80} \\
\hline Dry matter digestibility: $(\%)$ & 62.42 & 50.13 & 49.18 \\
Dry weight of forage: $W\left(\mathrm{~g} / \mathrm{m}^{2}\right)$ & 203.40 & 424.80 & 767.20 \\
Dry weight of digestible materials: $D\left(\mathrm{~g} / \mathrm{m}^{2}\right)$ & 126.96 & 212.95 & 377.31 \\
\hline
\end{tabular}

Dry matter digestibility: determined in vitro using rumen fluid of goats and pepsin. 


\section{Comparisons between two intervals in $\mathrm{Dg}$ and in $\mathrm{Bg}$}

Analytical results for accumulation of digestible materials and decreases in dry matter digestibility for the comparison between two intervals in Dg and in Bg are shown in Table 2.

Table 2. Comparisons between the first interval and the second interval in the accumulation of digestible materials and the decrease in dry matter digestibility in dallis grass and bermuda grass.

a) Analyses of the accumulation of digestible materials.

\begin{tabular}{lcccccc}
\hline Forages & \multicolumn{3}{c}{ Dallis grass } & \multicolumn{3}{c}{ Bermuda grass } \\
Interval & 1st (P) & 2nd (Q) & P/Q & 1st (R) & 2nd (S) & R/S \\
Length of interval (days) & 39 & 21 & & 39 & 21 & \\
\hline$\overline{\text { ARD }(\mathrm{g} / \mathrm{g} / \text { day })}$ & 0.0160 & -0.0031 & -5.2070 & 0.0073 & 0.0135 & 0.5428 \\
$\overline{\text { ARDS }}(\mathrm{g} / \mathrm{g} /$ day $)$ & 0.0237 & -0.0058 & -4.0818 & 0.0128 & 0.0258 & 0.4975 \\
$\mathrm{~S} \mathrm{ratio}(\mathrm{g} / \mathrm{g})$ & 0.6761 & 0.5300 & 1.2757 & 0.5719 & 0.5242 & 1.0910 \\
\hline
\end{tabular}

ARD: accumulation rate of $D$ per unit $W$.

ARDS: accumulation rate of $D$ per unit $S(S$ : source materials $=D+d W / d t)$.

$S$ ratio: the ratio of $S$ to $W$.

b) Analyses of the decrease in dry matter digestibility.

\begin{tabular}{lcccccr}
\hline Forages & \multicolumn{3}{c}{ Dallis grass } & \multicolumn{3}{c}{ Bermuda grass } \\
Interval & 1st (P) & 2nd (Q) & P/Q & 1st (R) & 2nd (S) & R/S \\
\hline DDMD & 0.1247 & 0.1397 & 0.8927 & 0.1229 & 0.0095 & 12.9452 \\
FG index & 0.6849 & 0.1331 & 5.1455 & 0.5212 & 0.4463 & 1.1678 \\
DDMPD index & 0.1821 & 1.0496 & 0.1735 & 0.2358 & 0.0213 & 11.0852 \\
\hline
\end{tabular}

DDMD: the decrease in dry matter digestibility.

FG index: forage growth index.

DDMPD index: index for the decrease in dry matter partition into digestible materials.

(1) Dg: As shown in Table 2a, $\overline{A R D}$ over the 1st interval was 0.0160 , but that over the 2nd interval showed negative value $(-0.0031)$. $\overline{\mathrm{ARDS}}$ was 0.0237 for the 1 st interval and -0.0058 for the 2nd interval. $\overline{\mathrm{S} \text { ratio }}$ in the 1 st interval (0.6761) was slightly higher than that in the 2nd interval (0.5300). Therefore, higher $\overline{\mathrm{ARD}}$ in the 1 st interval compared to the 2nd interval was mainly due to higher $\overline{\mathrm{ARDS}}$ in the 1st interval.

As shown in Table 2b, DDMD showed only a small difference between two intervals (0.1247 versus 0.1397$)$. FG index was higher in the 1st interval than in the 2nd interval (0.6849 versus 0.1331$)$, but DDMPD index in the 1 st interval $(0.1821)$ was lower compared to that in the 2nd interval (1.0496). Thus, similar DDMD between two intervals was due to the offset effect between FG index and DDMPD index.

(2) Bg: As shown in Table 2a, $\overline{\text { ARD }}$ was lower in the 1st interval than in the 2nd interval (0.0073 versus 0.0135$)$. $\overline{\mathrm{ARDS}}$ in the 1st interval (0.0128) was lower compared to that in the 2nd interval (0.0258). $\overline{\mathrm{S} \text { ratio }}$ was similar between two intervals $(0.5719$ versus 
0.5242). Therefore, lower $\overline{\mathrm{ARD}}$ in the 1st interval than in the 2nd interval was due to lower $\overline{A R D S}$ in the 1st interval.

As shown in Table 2b, there was larger DDMD in the 1st interval compared to the 2nd interval (0.1229 versus 0.0095$)$. FG index in the 1 st interval (0.5212) was slightly higher than that in the 2nd interval (0.4463). DDMPD index in the 1st interval was higher compared to that in the 2nd interval ( 0.2358 versus 0.0213 ). Thus, larger DDMD in the 1st interval than in the 2nd interval was mainly due to higher DDMPD index in the 1st interval.

\section{Comparisons between $\mathrm{Dg}$ and $\mathrm{Bg}$ in each of two intervals}

Analytical results for accumulation of digestible materials and decreases in dry matter digestibility for the comparison between two grasses over the 1st interval and over the 2nd interval are shown in Table 3.

(1) First interval: As shown in Table $3 a, \overline{A R D}$ in $D g$ was higher than that in $\mathrm{Bg}$ $(0.0160$ versus 0.0073$)$. $\overline{\text { ARDS }}$ in Dg (0.0237) was higher compared to that in $\mathrm{Bg}$ (0.0128). $\overline{\mathrm{S} \text { ratio }}$ was slightly higher in $\mathrm{Dg}$ than in $\mathrm{Bg}(0.6761$ versus 0.5719$)$. Therefore, higher $\overline{\mathrm{ARD}}$ in Dg than in Bg was mainly due to higher $\overline{\mathrm{ARDS}}$ in Dg.

As shown in Table 3b, DDMD was almost the same between Dg and Bg $(0.1247$ versus 0.1229). FG index in Dg (0.6849) was higher than that in Bg (0.5212), but DDMPD index

Table 3. Comparisons between dallis grass $(\mathrm{Dg})$ and bermuda grass $(\mathrm{Bg})$ in the accumulation of digestible materials and the decrease in dry matter digestibility in each of two intervals.

a) Analyses of the accumulation of digestible materials.

\begin{tabular}{lcccccc}
\hline Interval (days) & \multicolumn{3}{c}{ 1st (39) } & \multicolumn{3}{c}{ 2nd (21) } \\
Forages & $\mathrm{Dg}(\mathrm{P})$ & $\mathrm{Bg}(\mathrm{R})$ & $\mathrm{P} / \mathrm{R}$ & $\mathrm{Dg}(\mathrm{Q})$ & $\mathrm{Bg}(\mathrm{S})$ & $\mathrm{Q} / \mathrm{S}$ \\
\hline$\widehat{\mathrm{ARD}}(\mathrm{g} / \mathrm{g} /$ day $)$ & 0.0160 & 0.0073 & 2.1817 & -0.0031 & 0.0135 & -0.2274 \\
$\overline{\mathrm{ARDS}}(\mathrm{g} / \mathrm{g} /$ day $)$ & 0.0237 & 0.0128 & 1.8456 & -0.0058 & 0.0258 & -0.2249 \\
$\mathrm{~S} \mathrm{ratio}(\mathrm{g} / \mathrm{g})$ & 0.6761 & 0.5719 & 1.1821 & 0.5300 & 0.5242 & 1.0110 \\
\hline
\end{tabular}

ARD: accumulation rate of $D$ per unit $W$.

ARDS: accumulation rate of $D$ per unit $S(S$ : source materials $=D+d W / d t)$.

$S$ ratio: the ratio of $S$ to $W$.

b) Analyses of the decrease in dry matter digestibility.

\begin{tabular}{lcccccr}
\hline Interval (days) & \multicolumn{3}{c}{ 1st (39) } & \multicolumn{3}{c}{ 2nd (21) } \\
Forages & Dg (P) & $\operatorname{Bg}(\mathrm{R})$ & $\mathrm{P} / \mathrm{R}$ & $\mathrm{Dg}(\mathrm{Q})$ & $\mathrm{Bg}(\mathrm{S})$ & \multicolumn{1}{c}{$\mathrm{Q} / \mathrm{S}$} \\
\hline DDMD & 0.1247 & 0.1229 & 1.0148 & 0.1397 & 0.0095 & 14.7158 \\
FG index & 0.6849 & 0.5212 & 1.3140 & 0.1331 & 0.4463 & 0.2982 \\
DDMPD index & 0.1821 & 0.2358 & 0.7723 & 1.0496 & 0.0213 & 49.3441 \\
\hline
\end{tabular}

DDMD: the decrease in dry matter digestibility.

FG index: forage growth index.

DDMPD index: index for the decrease in dry matter partition into digestible materials. 
was lower in Dg than in Bg (0.1821 versus 0.2358). Thus, almost the same DDMD between Dg and Bg was due to the offset effect between FG index and DDMPD index.

(2) Second interval: As shown in Table $3 \mathrm{a}, \overline{\mathrm{ARD}}$ for $\mathrm{Dg}$ was -0.0031 and that for $\mathrm{Bg}$ was 0.0135 . ARDS was -0.0058 for Dg and 0.0258 for $\mathrm{Bg}$. $\mathrm{S}$ ratio was similar between two grasses (0.5300 versus 0.5242). Therefore, lower (negative) $\overline{\mathrm{ARD}}$ in Dg compared to Bg was due to lower (negative) $\overline{\text { ARDS }}$ in Dg.

As shown in Table 3b, DDMD was larger in Dg than in Bg (0.1397 versus 0.0095). FG index in Dg (0.1331) was lower compared to that in Bg (0.4463), but DDMPD index was much higher in Dg than in Bg (1.0496 versus 0.0213). Thus, larger DDMD in Dg than in Bg was due to higher DDMPD index in Dg.

It was found that the present analyses drew useful information, from simple data on tropical grasses (Table 1), about the accumulation of digestible materials and dry matter digestibility which changed with growth of grasses (Tables 2 and 3). Thus, the method presented in this study may give analytical information enough to estimate the relationship between growth of grasses and digestibility decreases, if there is no need to investigate the rate and the extent of lignification and indigestion of grasses that largely affect the decrease in dry matter digestibility.

\section{Conclusions}

It is suggested from this study that the proposed method gives macro analyses of the accumulation of digestible materials and the decrease in dry matter digestibility in the growth of tropical grasses. The present analytical method should be applied to other tropical and temperate forages.

\section{ACKNOWLEDGEMENTS}

We wish to thank Dr. Mitsuhiro Furuse who encouraged us during the writing this paper and Mr. Yasukatsu Yano for his skilled technical assistance in the present work.

\section{REFERENCES}

Hunt, R. 1990 Compounded growth rates. In "Basic Growth Analysis", Unwin Hyman Ltd., London, pp. 55-72

Masuda, Y. 1985 Analysis of dry matter digestibility of green panic as affected by the change in temperature. Proc. XV Int. Grassl. Congr., 1009-1011

Minson, D. J. 1990 Digestible energy of forage. In "Forage in Ruminant Nutrition", Academic Press, Inc., San Diego, pp. 85-149

Shimojo, M., Y. Masuda, T. Bungo, T. Kawamura and I. Goto 1995 Analytical expression for formation of indigestible materials and increase in dry matter indigestibility with growth of some tropical grasses. J. Fac. Agr., Kyushu Univ., 40: 179-188

Shimojo, M., T. Bungo, Y. Imura, M. Tobisa, N. Koga, Y. Nakano, I. Goto and Y. Masuda 1997 a An analysis of digestibility change with growth of forage. In "Present and future of rumen research", Proc. First Joint Symp. Japan and Korea on Rumen Metab. Physiol., P-11

Shimojo, M., Y. Imura, M. Tobisa, N. Koga, T. Bungo, Y. Nakano, T. Nishihira, I. Goto and Y. Masuda 1997b Formation of indigestible materials and increase in dry matter indigestibility in the growth of two tropical forages. J. Fac. Agr., Kyushu Univ., 42: 95-99

Shimojo, M., Y. Imura, T. Bungo, M. Tobisa, N. Koga, S. Tao, M. Yunus, Z. Yin, Y. Nakano, I. Goto and Y. 
Masuda 1998a Formation of indigestible materials from digestible materials and photosynthates in the growth of Rhodes grass (Chloris gayana Kunth). J. Fac. Agr, Kyushu Univ., 42: in press

Shimojo, M., T. Bungo, Y. Imura, M. Tobisa, N. Koga, S. Tao, M. Yunus, Z. Yin, Y. Nakano, I. Goto and Y. Masuda 1998b Relationship between two different-type equations analyzing increase in dry matter indigestibility with growth of forages. J. Fac. Agr., Kyushu Univ, 42: in press

Van Soest, P. J. 1982 Nutritional quality. In "Nutritional Ecology of the Ruminant", Cornell University Press, New York, pp. 23-74 